White Paper Series

\title{
Ranking Hospital Community Benefit Investment
}

\section{EXECUTIVE SUMMARY}

Hospitals are expected (and in the case of nonprofit hospitals, legally obligated) to provide financial assistance to uninsured or low-income patients and invest in the health of their surrounding community. However, a lack of transparency and accountability make it difficult to know to what extent hospitals are investing in community health.

As part of the Lown Institute Hospitals Index, we created a metric to measure hospitals' commitment to community health investment and to ensure low-income and uninsured patients get the care they need based on their spending on charity care, other community benefits, and their share of patient revenue from Medicaid patients. Our analysis includes private nonprofit, public, and for-profit hospitals using data from the Internal Revenue Service (IRS) and Centers for Medicare and Medicaid Services (CMS) for 2016. Although the IRS recognizes several categories of community benefit spending, we focus only on those considered most impactful for community health according to a review of the literature and expert opinion.

We use this metric to rank hospitals and compare community benefit investment across hospital type and region. An analysis of the Lown Index Community Benefit metric reveals several patterns in community benefit investment. In general, larger hospitals, teaching hospitals, and urban hospitals have significantly greater community benefit scores on average, compared to smaller, non-teaching, rural, and critical access hospitals. Nonprofit hospitals are highly represented among the top hospitals in community benefit investment, but overall do not have scores significantly different from for-profit hospitals.

Our analysis supports previous research which finds wide variation in community benefit spending. When excluding unreimbursed costs of government programs and health professions education - programs for which hospitals already receive payment-hospitals on average spent 2.8 percent of their total expenses on charity 
care and other community health investments. However, the amount hospitals spent ranges widely; top-spending hospitals spent 15 percent or more of their expenses on charity care and other community benefits, while about 150 hospitals spent less than 0.1 percent.

We consider several policy recommendations to increase transparency and accountability. Standardizing community benefit data collection, adding reporting requirements for hospitals, and connecting community benefit spending to health needs identified in community health needs assessments would be promising steps toward making hospital community health investments more impactful.

\section{INTRODUCTION}

Hospitals are not just providers of health care services, they are deeply embedded in the communities they serve, as employers, taxpayers, and purchasers of goods and services, as well as forming part of the physical environment. As "anchor institutions," hospitals are widely perceived as pillars of their communities with a responsibility not just to the patients they treat, but also to the health and vitality of the wider population. The language of social responsibility and community health is generally incorporated into hospital mission statements, emphasizing their commitment to service that goes beyond the provision of medical services. ${ }^{1}$

This commitment is also a legal expectation for nonprofit hospitals, which enjoy billions of dollars each year in tax breaks on the condition of providing community benefits. ${ }^{2}$ Though the definition of a community benefit is not well established, the extent to which nonprofit hospitals actually work to improve community health and well-being is known to vary widely. While some hospitals provide ample financial aid for low-income patients or contribute to improving their community's environment and economy, many others are overcharging poor and inadequately insured patients, closing clinics in underserved neighborhoods, breaking up unions of hospital workers, and taking other actions that boost the hospital's profit at the expense of community well-being. ${ }^{3-5}$

Only rarely are hospitals held accountable when they fail to fulfill their obligation towards their communities. While there have been occasional stories in the media questioning whether or not a hospital deserves its tax-free status, no hospital ranking takes into account commitment to community benefits specifically and social mission writ large when evaluating hospitals. ${ }^{6}$ 
The Lown Institute Hospitals Index (LIHI) aims to provide data so that communities may hold their hospitals accountable for their investments in achieving their social mission. The Lown Index is the first hospital ranking to create a holistic view of American hospitals, ranking them not only on patient outcomes, but also on the value of their care, and their commitment to social mission, or what we call civic leadership. (For more information on the LIHI and to see the full data set, metrics list, and methodology, go to www.LownHospitalsIndex.org.)

This white paper focuses on one aspect of a hospital's commitment to civic leadership: community benefit spending. Our analysis provides insight into how much hospitals are spending on activities to serve uninsured and low-income patients and improve community health and well-being. In this paper, we measure what we deemed to be meaningful community benefit spending by combining data from IRS forms and hospital cost reports. We analyze community benefit spending across 3,362 nonprofit and for-profit hospitals for 2016, the most recent year for which full data are available. We identify trends in hospital community benefit spending across types of hospital, hospital size, and location. We include recommendations for policy and research to hold hospitals accountable and address data limitations. And for the first time, we list the best and worst hospitals in terms of community benefit spending.

\section{WHAT IS COMMUNITY BENEFIT SPENDING?}

In addition to providing medical services to patients, community benefit spending is one of the principal ways in which nonprofit hospitals are expected to serve the people in their surrounding communities. The IRS requires nonprofit hospitals to engage in activities that improve the health of their local communities, and to record this spending on Form 990 on Schedule H, Part I. This requirement has been in place since the passage of the Affordable Care Act (ACA) in 2010.

Prior to 1969, the IRS allowed hospitals to qualify for tax-exempt status if they provided "free or reduced-cost care to patients unable to pay for it...to the extent of [the hospital's] financial ability." 7 In 1969, the IRS created the term "community benefit" to expand qualifying spending beyond charity care and include other activities that improve the health of the community (see Box: IRS categories of community benefit spending). The types of spending now included by the IRS are charity care (care provided to patients who cannot pay), Medicaid shortfall (the difference between the amount reimbursed for Medicaid services and the hospital's estimate of its cost of care), health professions education, shortfall from participation in other means-tested government programs (such as the State Children Health Insurance Program (CHIP)), 
research, subsidized clinical health services, and community health improvement activities and community benefit operations.

\section{IRS Categories of Community Benefit Spending}

Included in the LIHI Community Benefit measure:

- Financial assistance/charity care: Free or discounted health services for patients unable to pay the full amount.

- Cash and in-kind contributions for community benefit: Investments in health care organizations specifically for community health activities.

- Subsidized clinical health services: Health care services provided to meet identified community needs, despite a financial loss to the organization.

- Community health improvement services: Activities subsidized by the hospital for the purpose of improving community health, which don't generate revenue for the hospital. Examples include health fairs, free immunizations, interpreter services, and community health education. Also included is the cost of maintaining community benefit operations at the hospital.

- Community-building activities, activities designed to improve community health/safety, are not usually counted in a hospital's total community benefit spending by the IRS but are included in the LIHI Community Benefit measure. These activities include economic development, environmental improvements, childcare, and advocacy.

Not included in the LIHI Community Benefit measure:

- Medicaid shortfall: The difference between cost of care and amount reimbursed for Medicaid services.

- Health professions education: Programs that provide training or continuing education for health professionals.

- Research: The cost of internally-funded or nonprofit-funded research.

- Other means-tested government health programs: Unreimbursed cost of care for programs such as the Children's Health Insurance Program.

Community-building activities, which seek to improve the social determinants of health within a community, are listed on part II of Schedule $\mathrm{H}$ and are generally not included in the community benefit spending total. These may include projects such as building housing for homeless patients, building parks and playgrounds, sponsoring farmers markets, workforce development, subsidized childcare, and other activities that help communities address the upstream social factors that impact health.

Although community-building activities are not counted by the IRS as community benefits, addressing community conditions such as food and financial security, housing stability, and environmental conditions has great potential to improve community health in the long term. ${ }^{8}$ Thus, our analysis includes spending on community-building activities within our measurement of community benefits. 
Previous research on community benefits has uncovered several problems with hospital community benefit spending and reporting:

\section{The amount of community benefit spending among nonprofit hospitals varies widely.}

Many nonprofit hospitals are reaping the benefits of tax breaks while contributing little to community health.4,8-11 The average level of community benefit spending among nonprofit hospitals is estimated at 7.5-8.1 percent of total expenses. ${ }^{9-12}$ However, there is substantial variation, ranging from 20 percent or more as a portion of operating expenses to less than 1 percent. ${ }^{10,11}$ This variation does not appear to be based on differences in local community health or socioeconomic needs. ${ }^{0,12}$ Nor is it based on hospital resources: More profitable hospitals offer less charity care as a share of their net revenue compared to less successful hospitals. ${ }^{13}$

2. Hospitals vary in how they spend on community benefit investments with some spending much more on programs that directly impact community health.

As described above, there are many different types of spending that the IRS counts as fulfillment of the community benefit requirement. However, not all of these spending types are equally meaningful when it comes to community health. For example, spending on health professions education and research is beneficial to public health and the generation of medical knowledge, but does not benefit members of the community directly, and may perpetuate overinvestment in specialty care rather than much-needed primary care. Yet for many academic medical centers, the largest category of community benefit spending is training health professionals.

Other categories of community benefit spending — such as Medicaid shortfall and shortfall from other government programs-have drawn criticism from researchers because hospitals are already reimbursed for this spending. Indeed, with the expansion of Medicaid in 2014, many hospitals experienced a windfall as states began reimbursing hospitals for care they previously provided free as charity care. Yet in many cases community benefit spending declined, even as hospital revenue increased due to Medicaid expansion. ${ }^{10,14,15}$ In states where Medicaid expansion occurred, charity care has generally declined and Medicaid shortfall increased as a share of community benefit spending..$^{11,16}$ It does not appear that hospitals are reallocating charity care funds towards broad community health initiatives or social determinants of health as policymakers hoped would happen as a result of the ACA. $\cdot{ }^{10}$ Across hospitals, less than 1 
percent of community benefit spending is devoted to community-building activities, despite their considerable potential to improve community health. ${ }^{8,10,12,17,18}$

\section{There is little accountability from the government to incentivize hospital community benefit spending.}

Starting in 2012, the ACA began requiring hospitals to conduct Community Health Needs Assessments (CHNAs) every three years to gauge community health needs and create an implementation strategy to address them. In addition, hospitals are required to develop a financial assistance policy outlining eligibility for free or discounted care for patients who are uninsured or otherwise unable to pay. ${ }^{7}$

Despite the additional requirements implemented under the ACA, government standards for community benefit spending put little pressure on hospitals to invest substantially in community health. There is no federal requirement for how much hospitals must invest in community benefits, or what percentage of their expenses, nor are there requirements for the type of community benefits they must invest in. Although the CHNA process requires hospitals to identify and address community health needs, there is no requirement that hospital spending on community benefits must correspond to these health needs.

Some states have more extensive community benefit requirements, but only five currently require a minimum level of spending. ${ }^{19}$ Further, federal enforcement of community benefit spending standards is minimal. Since the ACA was passed, the IRS has revoked the tax-exempt status of only two hospitals for inadequate community benefit investments or reporting. ${ }^{20-22}$ The lack of clear requirements for amount and type of community benefit spending, as well as the lack of strict enforcement of standards have made it difficult to discern the extent to which nonprofit hospitals are actually serving their communities.

The general lack of transparency is even more glaring for state and public hospitals (public hospitals are owned and run by municipal, county, or state governments), which as public entities do not report their community benefit spending to the IRS. This makes it very difficult to track public hospital spending on types of community benefits such as subsidized health services, community health improvement, and community building. Some of these hospitals, such as the University of California's six hospitals, represent a substantial portion of Medicaid and Medicare payments in a state. For such public institutions, the need for transparency would seem essential. 


\section{Community benefit reporting methods are not standardized across hospitals and states.}

Because of differences in defining what counts as a community benefit and differences in how the costs of these community benefits are calculated, the way in which community benefit spending is reported varies across hospitals and states. For example, Maryland's unique all-payer rate setting policy for hospitals includes reimbursements for hospital spending on uncompensated care and health professions education. Yet Maryland hospitals are instructed not to include these reimbursements on their Form 990 when reporting community benefit spending, making it difficult to compare Maryland hospitals to those in other states. ${ }^{23}$

Additionally, reporting of Medicaid Disproportionate Share Hospital (DSH) payments (payments made to hospitals if they serve a large proportion of Medicaid patients) on Form 990 is not standardized; some hospitals report these payments, while others do not. ${ }^{11}$ Hospitals also differ in how they define which patients are eligible for charity care and how they calculate the cost of providing charity care, leading to wide variation in how they report community benefit spending. ${ }^{19,20}$

\section{METHODOLOGY}

\section{DATA SOURCES AND METHODS}

Our community benefit analysis is based on three metrics:

1) Community benefit spending as a share of total expenses, using data from IRS Form 990;

2) Charity care spending as a share of total expenses, using data the Centers for Medicare and Medicaid Services (CMS) healthcare cost reports; and

3) Medicaid revenue as a share of total patient revenue, using CMS healthcare cost reports.

Medicaid revenue as a share of total patient revenue was added to the overall metric to give credit to hospitals, especially in Medicaid expansion states, that serve a large proportion of Medicaid patients. While the IRS Form 990 category "Unreimbursed Medicaid Spending" is often seen as a proxy for serving Medicaid patients, we believe that measuring Medicaid patients as a share of patients served is a clearer depiction of providing care to low-income patients. Community benefit spending information for Maryland hospitals was taken from the state's Health Services Cost Review Commission data on community benefits, which adjusts for these reimbursements. 
The proportion of community benefit spending as a share of total expenses from the state reports were weighted (2/3) with Medicaid revenue from CMS healthcare cost reports weighed at $(1 / 3)$.

The weighting of each metric depended on availability of data. Most hospitals had data for all three metrics, and each metric was weighted equally ( $1 / 3$ each) to create a final score. However, public hospitals and for-profit hospitals are not required to file Form 990, and many did not have IRS data available. For these hospitals, charity care spending as a share of total expenses was given $2 / 3$ of the weight, and Medicaid revenue as a share of total patient revenue was $1 / 3$.

Hospital data from CMS healthcare cost reports and IRS Form 990 was excluded if the hospital reported more community benefit spending or more charity care than total expenses, or if the hospital reported negative community benefit spending. In these cases, the other data sources were given greater weight for the overall score.

\section{MEASURING MEANINGFUL COMMUNITY BENEFIT SPENDING}

We excluded the following categories of community benefits from the IRS 990 data: unreimbursed Medicaid spending, unreimbursed cost of other means-tested programs, research, and health professions education. We kept charity care, subsidized health care services, contributions to community organizations, and community health improvement activities from the IRS data.

Our reasons for excluding some categories of community benefit spending are as follows. Although Medicaid shortfall is considered a community benefit by the IRS, researchers have questioned whether this metric is an accurate measure of a hospital's commitment to serving its community. ${ }^{11}$ Medicaid payments for a given service are generally lower than commercial payments, but states set their Medicaid rates at a level believed to be sufficient to cover hospital costs of delivering care. Some observers have pointed out that if hospital discounts to private insurers or Medicare are not community benefits, then Medicaid discounts should also not be considered community benefits. ${ }^{11}$ Indeed, hospitals' willingness to take these patients reflects that these payments are reasonable. Rather than using Medicaid shortfall as a proxy for hospitals' inclusion of Medicaid patients, we instead measured the proportion of patient revenue from patients insured through Medicaid. Hospitals will sometimes also list shortfall from other means-tested government health programs, such as CHIP. These rates are also set at a level the government considers reasonable and sufficient to cover the cost of care, and thus should not be included as a community benefit. ${ }^{9}$ 
With regard to health professions training, several researchers have pointed out that the cost of training doctors and other health professionals should only be seen as a community benefit if we believe that there would be an insufficient number of health care professionals without this tax break for teaching hospitals. ${ }^{24}$ This seems unlikely. The professionals being trained at hospitals provide the hospital itself with relatively inexpensive labor. Indeed, many teaching hospitals could not function without the many residents who provide an estimated $40-60 \%$ of direct patient care. ${ }^{25}$ In addition, the federal government already subsidizes the salaries of most residents through the Direct Medical Graduate Education (DGME) program.

Additionally, while hospitals are required on IRS Form 990 to discount the DGME payments that Medicare provides to teaching hospitals, many do not report the indirect medical education (IME) payments they also receive from Medicare. IME adjustments provide additional funds to teaching hospitals for each Medicare patient discharge to reflect the higher patient care costs of teaching hospitals relative to nonteaching hospitals.

The Medicare Payment Advisory Commission (MedPAC), an independent agency which advises Congress on Medicare issues, found that IME payments are set at twice the level justified by hospital need, giving teaching hospitals an excess $\$ 3.5$ billion in payments each year. ${ }^{26}$ This suggests that the amount teaching hospitals report on Form 990 for "unreimbursed health professions education" is often inflated.

We excluded money spent on medical research from the IRS data as well. Unreimbursed spending on research may be a public good, but there was insufficient information in the IRS forms to gauge whether or not an individual hospital's self-funded research was likely to have a direct impact on surrounding community health or social determinants of health.

\section{RESULTS}

For the 3,362 hospitals ranked, the average level of charity care and other meaningful community benefit spending as a share of total expenses was 2.8 percent. This level of spending is significantly lower than previous analyses of nonprofit community benefit spending. This is to be expected because our analysis removed Medicaid shortfall and health professions education, which are two of the largest categories of community benefit spending reported by private nonprofit hospitals. ${ }^{16}$

Our analysis supports previous research, which finds wide variation in community benefit spending. While the average proportion of our community benefit spending 
measure as a share of expenses is 2.8 percent, top-spending hospitals spent 15 percent or more of their expenses on community benefits, and about 150 hospitals spent less than 0.1 percent of their expenses on charity care and other community benefits.

\section{TOP HOSPITALS}

Our novel community benefit ranking - a composite of hospital spending on charity care, other community benefit spending, and Medicaid share of patient revenueallows comparisons of individual hospitals and hospital types.

Table 1 contains the top 20 hospitals ranked by community benefit score. The majority are large or very large size teaching hospitals as measured by bed count (200 or more beds). All but one (Southern Ohio Medical Center) are in an urban location, all but one (Pacifica Hospital of the Valley) are nonprofit hospitals, and all of the hospitals are acute care hospitals. It is not surprising that public hospitals are well-represented in the top list, as they often bear a disproportionate burden of caring for Medicaid patients and the uninsured. Hospitals in Texas, California, and New York are highly represented in this top list as well.

As with the top 20 list, among all of the 3,362 hospitals, we found significantly greater community benefit scores, on average, among larger hospitals, teaching hospitals, urban hospitals, and acute care hospitals compared to smaller, non-teaching, rural, and critical access hospitals (See Table 2). However, the community benefit scores of for-profit and nonprofit hospitals are not significantly different. Looking at all hospitals, New York hospitals still have high scores on average, while California and Texas drop into the middle range. 
Table 1: Top 20 hospitals ranked by community benefit score

\begin{tabular}{|c|c|c|c|c|c|c|}
\hline Rank & Hospital & State & City & Ownership Type & Teaching Class & Hospital size \\
\hline 1 & Harris Health System & TX & Houston & Public nonprofit & Minor & Very large \\
\hline 2 & $\begin{array}{l}\text { Ochsner LSU Health } \\
\text { Monroe }\end{array}$ & LA & Monroe & $\begin{array}{l}\text { Private } \\
\text { nonprofit }\end{array}$ & Minor & Medium \\
\hline 3 & $\begin{array}{l}\text { Martin Luther King, } \\
\text { JR. Community } \\
\text { Hospital }\end{array}$ & CA & $\begin{array}{l}\text { Los } \\
\text { Angeles }\end{array}$ & $\begin{array}{l}\text { Private } \\
\text { nonprofit }\end{array}$ & Non-teaching & Medium \\
\hline 4 & $\begin{array}{l}\text { Elmhurst Hospital } \\
\text { Center }\end{array}$ & NY & Elmhurst & Public nonprofit & Minor & Very large \\
\hline 5 & $\begin{array}{l}\text { Queens Hospital } \\
\text { Center }\end{array}$ & NY & Jamaica & Public nonprofit & Minor & Large \\
\hline 6 & $\begin{array}{l}\text { Parkland Health and } \\
\text { Hospital System }\end{array}$ & $\mathrm{TX}$ & Dallas & Public nonprofit & Major & Very large \\
\hline 7 & St Bernard Hospital & IL & Chicago & $\begin{array}{l}\text { Private } \\
\text { nonprofit }\end{array}$ & Non-teaching & Medium \\
\hline 8 & $\begin{array}{l}\text { North Central Bronx } \\
\text { Hospital }\end{array}$ & NY & Bronx & Public nonprofit & Minor & Large \\
\hline 9 & $\begin{array}{l}\text { Pacifica Hospital of } \\
\text { the Valley }\end{array}$ & CA & $\begin{array}{l}\text { Sun } \\
\text { Valley }\end{array}$ & For-profit & Non-teaching & Large \\
\hline 10 & $\begin{array}{l}\text { Woodhull Medical } \\
\text { and Mental Health } \\
\text { Center }\end{array}$ & NY & Brooklyn & Public nonprofit & Minor & Large \\
\hline 11 & JPS Health Network & $\mathrm{TX}$ & $\begin{array}{l}\text { Fort } \\
\text { Worth }\end{array}$ & Public nonprofit & Major & Very large \\
\hline 12 & $\begin{array}{l}\text { Metropolitan } \\
\text { Hospital Center }\end{array}$ & NY & $\begin{array}{l}\text { New } \\
\text { York }\end{array}$ & Public nonprofit & Minor & Large \\
\hline 13 & $\begin{array}{l}\text { LAC/Olive View- } \\
\text { UCLA Medical Center }\end{array}$ & CA & Sylmar & Public nonprofit & Minor & Large \\
\hline 14 & $\begin{array}{l}\text { Roseland Community } \\
\text { Hospital }\end{array}$ & IL & Chicago & $\begin{array}{l}\text { Private } \\
\text { nonprofit }\end{array}$ & Non-teaching & Medium \\
\hline 15 & $\begin{array}{l}\text { Lallie Kemp Medical } \\
\text { Center }\end{array}$ & LA & $\begin{array}{l}\text { Independ } \\
\text { ence }\end{array}$ & Public nonprofit & Minor & Very small \\
\hline 16 & Kern Medical Center & CA & $\begin{array}{l}\text { Bakersfie } \\
\text { ld }\end{array}$ & Public nonprofit & Minor & Medium \\
\hline 17 & $\begin{array}{l}\text { Bergen New Bridge } \\
\text { Medical Center }\end{array}$ & NJ & Paramus & Public nonprofit & Non-teaching & Very large \\
\hline 18 & $\begin{array}{l}\text { Southern Ohio } \\
\text { Medical Center }\end{array}$ & $\mathrm{OH}$ & $\begin{array}{l}\text { Portsmo } \\
\text { uth }\end{array}$ & $\begin{array}{l}\text { Private } \\
\text { nonprofit }\end{array}$ & Minor & Large \\
\hline 19 & $\begin{array}{l}\text { Arrowhead Regional } \\
\text { Medical Center }\end{array}$ & CA & Colton & Public nonprofit & Minor & Very large \\
\hline 20 & $\begin{array}{l}\text { Adventist Health } \\
\text { Reedley }\end{array}$ & CA & Reedley & Public nonprofit & Non-teaching & Very small \\
\hline
\end{tabular}


Table 2: Community benefit ranking by hospital type

\begin{tabular}{|l|c|c|l|}
\hline Hospital type & \multicolumn{1}{|c|}{$\begin{array}{c}\text { Number of } \\
\text { hospitals }\end{array}$} & \multicolumn{2}{|c|}{ Average Community Benefit Rank Percentile } \\
\hline & & Percentile & Significance \\
\hline $\begin{array}{l}\text { Major } \\
\text { teaching }\end{array}$ & 224 & 57.27 & $\mathrm{p}<0.01^{*}$ \\
\hline $\begin{array}{l}\text { Minor } \\
\text { teaching }\end{array}$ & 810 & 53.29 & $\mathrm{p}<0.01^{*}$ \\
\hline Non-teaching & 2320 & 48.18 & \\
\hline & & & \\
\hline Very Small & 883 & 44.68 & $\mathrm{p}<0.01^{* *}$ \\
\hline Small & 528 & 47.67 & $\mathrm{p}<0.01^{* *}$ \\
\hline Medium & 779 & 51.93 & \\
\hline Large & 730 & 52.79 & \\
\hline Very Large & 434 & 55.64 & \\
\hline & & & \\
\hline For-profit & 543 & 52.55 & $\mathrm{NS}$ \\
\hline Nonprofit & 2811 & 49.53 & $\mathrm{NS}$ \\
\hline & & & \\
\hline Urban & 2120 & 52.15 & $\mathrm{p}<0.001$ \\
\hline Rural & 1234 & 46.36 & \\
\hline & & & \\
\hline Acute Care & 2634 & 52.64 & $\mathrm{p}<0.001$ \\
\hline $\begin{array}{l}\text { Critical } \\
\text { Access }\end{array}$ & 728 & 40.44 & \\
\hline & & & \\
\hline
\end{tabular}

*Significantly different from non-teaching hospitals

** Significantly different from Medium, Large, and Very Large hospitals

*** Significantly different from Small and Very Small hospitals

Several patterns appear when comparing community benefit score by state (see Table 3). Hospitals in Medicaid expansion states had lower scores on the community benefit spending metric, on average, than those in non-expansion states, likely because they spent less on charity care. Similarly, many hospitals in states that did not expand Medicaid have high levels of charity care spending, and thus high community benefit spending scores.

However, there are some Medicaid-expansion states whose hospitals are both serving Medicaid patients and providing high levels of charity care and other community 
benefits. Connecticut, Delaware, Illinois, Indiana, Montana, New Jersey, New York, and Tennessee are all above-average on both metrics. On the other hand, some states such as Alabama, Arkansas, Iowa, Idaho, Kansas, Minnesota, Mississippi, North Dakota, Nebraska, Oklahoma, Pennsylvania, and Wisconsin hospitals have below-average rankings in both metrics.

Table 3: Average percentile rankings of community benefit score and its two subcomponents, by state

\begin{tabular}{|c|c|c|c|c|c|}
\hline State & $\begin{array}{l}\text { Number of } \\
\text { hospitals }\end{array}$ & $\begin{array}{l}\text { Overall LIHI } \\
\text { Community } \\
\text { Benefit Score }\end{array}$ & $\begin{array}{l}\text { Charity Care } \\
\text { and Other } \\
\text { Spending }\end{array}$ & $\begin{array}{c}\text { Medicaid } \\
\text { Revenue as Share } \\
\text { of Patient } \\
\text { Revenue }\end{array}$ & $\begin{array}{c}\text { Medicaid } \\
\text { Expansion in } \\
2016 ?\end{array}$ \\
\hline $\mathrm{AK}$ & 9 & 46.78 & 44.41 & 60.74 & Yes \\
\hline $\mathrm{AL}$ & 76 & 36.31 & 41.88 & 33.53 & No \\
\hline AR & 56 & 32.69 & 39.00 & 34.15 & Yes \\
\hline$A Z$ & 50 & 53.65 & 42.31 & 67.35 & Yes \\
\hline CA & 247 & 48.53 & 35.90 & 72.46 & Yes \\
\hline $\mathrm{CO}$ & 40 & 64.32 & 41.76 & 69.88 & Yes \\
\hline $\mathrm{CT}$ & 26 & 66.59 & 53.99 & 68.31 & Yes \\
\hline $\mathrm{DC}$ & 5 & 69.47 & 28.02 & 75.76 & Yes \\
\hline $\mathrm{DE}$ & 6 & 66.49 & 64.41 & 62.08 & Yes \\
\hline $\mathrm{FL}$ & 165 & 56.04 & 69.76 & 41.28 & No \\
\hline GA & 97 & 54.44 & 70.89 & 39.43 & No \\
\hline $\mathrm{HI}$ & 10 & 47.97 & 42.07 & 67.35 & Yes \\
\hline IA & 85 & 38.71 & 35.72 & 42.51 & Yes \\
\hline ID & 16 & 37.03 & 49.48 & 29.17 & No \\
\hline IL & 161 & 57.82 & 53.39 & 59.64 & Yes \\
\hline IN & 93 & 50.99 & 51.46 & 50.39 & Yes \\
\hline KS & 81 & 26.64 & 45.58 & 17.69 & No \\
\hline KY & 80 & 62.14 & 30.37 & 80.09 & Yes \\
\hline LA & 79 & 67.09 & 37.57 & 76.70 & Yes \\
\hline MA & 56 & 53.65 & 47.04 & 56.61 & Yes \\
\hline MD & 41 & 69.32 & 70.88 & 56.90 & Yes \\
\hline ME & 27 & 37.31 & 63.03 & 26.21 & No \\
\hline MI & 105 & 45.56 & 27.31 & 57.24 & Yes \\
\hline $\mathrm{MN}$ & 73 & 34.43 & 33.95 & 39.53 & Yes \\
\hline $\mathrm{MO}$ & 82 & 40.81 & 59.63 & 33.30 & No \\
\hline MS & 64 & 48.85 & 48.43 & 46.82 & No \\
\hline MT & 24 & 53.35 & 62.90 & 61.63 & Yes \\
\hline NC & 91 & 52.35 & 66.51 & 42.44 & No \\
\hline
\end{tabular}




\begin{tabular}{|l|c|c|c|c|c|}
\hline ND & 16 & 12.56 & 41.24 & 17.43 & Yes \\
\hline NE & 54 & 20.02 & 44.27 & 11.01 & No \\
\hline NH & 24 & 32.74 & 62.31 & 21.66 & Yes \\
\hline NJ & 62 & 59.85 & 63.25 & 56.90 & Yes \\
\hline NM & 27 & 64.40 & 36.98 & 72.48 & Yes \\
\hline NV & 23 & 43.61 & 33.97 & 73.59 & Yes \\
\hline NY & 143 & 68.44 & 51.47 & 72.05 & Yes \\
\hline OH & 124 & 58.45 & 43.71 & 64.02 & Yes \\
\hline OK & 67 & 46.50 & 48.85 & 41.94 & No \\
\hline OR & 45 & 50.58 & 46.00 & 69.56 & Yes \\
\hline PA & 134 & 43.18 & 38.84 & 48.56 & Yes \\
\hline RI & 9 & 65.45 & 35.94 & 72.95 & Yes \\
\hline SC & 47 & 50.25 & 63.06 & 37.78 & No \\
\hline SD & 22 & 31.78 & 68.00 & 20.05 & No \\
\hline TN & 81 & 60.23 & 63.66 & 56.77 & No \\
\hline TX & 221 & 54.59 & 69.56 & 34.74 & No \\
\hline UT & 20 & 32.85 & 54.78 & 29.05 & No \\
\hline VA & 70 & 45.24 & 71.68 & 28.14 & No \\
\hline VT & 10 & 51.03 & 57.82 & 45.32 & Yes \\
\hline WA & 62 & 45.50 & 36.95 & 65.78 & Yes \\
\hline WI & 101 & 37.80 & 45.49 & 35.49 & No \\
\hline WV & 41 & 61.69 & 27.75 & 69.58 & Yes \\
\hline WY & 14 & 35.48 & 59.07 & 31.25 & No \\
\hline
\end{tabular}

\section{DISCUSSION}

Our analysis adds to the evidence that hospitals vary widely in their community benefit spending levels, and that the nonprofit tax exemption may be too blunt an instrument for encouraging meaningful community benefit spending. In a 2018 study, Herring et al. estimate that tax exemptions for private nonprofits are worth 5.9 percent of their total expenses on average. ${ }^{9}$ When excluding unreimbursed costs of government programs and health professions education, we find that only about one-eighth of nonprofit hospitals are reaching this threshold.

While nonprofit hospitals are highly represented among the best hospitals in community benefit investment, the scores of nonprofit hospitals overall are not significantly different from those of for-profit hospitals, according to our analysis. This highlights the fact that many nonprofits could be doing more to invest in community health, given the significant tax exemptions they receive. 
Our results support previous research showing greater rates of community benefit spending among larger teaching hospitals in urban areas. ${ }^{9,16,27,28}$ While differences in community benefit spending by hospital type may reflect differences in hospitals' priorities and willingness to spend, it is likely that resource availability and financial security plays a large role in these disparities as well. Large teaching hospitals in urban areas likely have more resources to spend on community benefits, while small critical access hospitals in rural areas may not have these resources available. The financial vulnerability of CAHs and the lack of dedicated staff to organize community benefits activities at these hospitals are factors that likely contribute to these differences..$^{27,28}$

The disparities in charity care and other community benefit spending on a state level suggest that the burden of uncompensated care on hospitals has been eased in Medicaid expansion states. While some hospitals may argue that they are spending less on charity care but more on Medicaid shortfall, it is still the case that these hospitals are now being paid to care for patients who previously provided no revenue. This windfall should give hospitals in Medicaid expansion states an opportunity to either adjust their financial assistance policies to include more underinsured patients, or devote more resources to community health improvement and community-building activities. ${ }^{14,16}$ The relatively large community benefit contributions of hospitals in Delaware, Maryland, Montana, and New Jersey (in which Medicaid was expanded) suggest that hospitals in expansion states can contribute financial assistance and other community benefits as well as care for Medicaid patients.

\section{POLICY IMPLICATIONS}

Several regulatory actions would improve transparency around community benefit spending. Among experts we talked to, one of the highest-priority policy changes identified is requiring that hospitals within systems file with the IRS and report their community benefit spending individually, rather than as part of the larger hospital system. This would allow local policymakers and community leaders to understand more fully what local hospitals are spending on community health and ensure they are paying their fair share.

The IRS should also take steps to standardize reporting of community benefit spending categories, such as ensuring that all hospitals report indirect revenues received for health professions education. Community-building activities in which hospitals engage in or pay for should be required reporting on tax forms to give hospitals credit for the work they are doing and provide a larger incentive to spend on community conditions and report this spending. 
The federal government and/or states could also follow the lead of states that have added community benefit requirements for nonprofit hospitals. According to our analysis, it does not appear that the few states with minimum required levels of community benefit spending (IL, NV, PA, TX, UT) have greater levels of community benefit spending as a share of total expenses, compared to hospitals in other states. However, a more focused and tailored approach could increase accountability. For example, Maryland-one of the top hospitals in community benefit score-requires that hospitals report community benefit spending to their state health services commission with a detailed breakdown of spending in community benefit categories, descriptions of their community benefit initiatives, and efforts to evaluate the effectiveness of these initiatives.

Another promising example is Oregon's recent legislation requiring hospitals to provide charity care for all patients earning up to 200 percent of the federal poverty level. Each Oregon hospital is also required to meet with the state Health Authority to establish a community benefit spending minimum. ${ }^{29}$ This individualized approach allows the state to establish clear expectations for spending based on each hospital's profit margin and community needs. Such a process could keep hospitals accountable for their share of community benefit spending to the best of their financial ability.

Tracking the total amount that hospitals spend on community benefits is important, but so is ensuring that the money is spent wisely. Hospitals are required by the IRS to conduct Community Health Needs Assessments (CHNAs) to uncover community health needs. However, there is very little guidance on a standardized CHNA process, and on ensuring that process is truly driven by community needs. There is also little evidence that hospitals are using their CHNAs to direct their community benefit spending toward the actual needs of the community; practically no data exist to evaluate whether community benefit spending has any positive effect on community health. Local and state policymakers could take steps to improve transparency and accountability, such as requiring hospitals to record how much community benefit spending goes to priority issues identified in the CHNA. Ideally, hospitals should be spending the vast majority of their meaningful community benefits on the most urgent needs and/or those on which the hospital can have the greatest impact.

\section{LIMITATIONS}

While the measurement of community benefits has improved since the ACA clarified reporting requirements for IRS Form 990, there are still several limitations to the data available on hospital community benefit spending. For hospitals that did not file a Form 990, their score was based on charity care as a share of total expenses and share 
of Medicaid revenue, but we do not have the data available to take into account other types of community benefits on which public and for-profit hospitals are spending. Therefore, community benefit spending of public and for-profit hospitals may be undercounted if they are spending a significant amount of money on other forms of community benefit. Additionally, as previously mentioned, there are many hospital systems that file as a group, and thus their community benefit spending on Form 990 is not broken down by individual hospital.

Second, there are no reliable data for all hospitals regarding their billing and collection practices. Hospitals (even nonprofits) commonly overcharge patients who are eligible for charity care and sue eligible patients for unpaid bills. These practices go against the social mission of nonprofit hospitals and threaten the financial health of patients and community health. ${ }^{30}$ However, our analysis cannot capture this information because no centralized data exist on hospital billing and collection practices. While IRS Form 990 includes questions regarding hospital billing practices, no hospital reported on the form that they had engaged in aggressive collections.

Third, we can only measure the amount of spending on community benefits, not the impact that spending had on community health. While we have focused on a few categories of community benefits deemed more meaningful, we lack data on whether the spending by top hospitals is directed towards community health priorities identified in the CHNA. We hope our research will facilitate efforts to increase transparency around hospital community benefit spending, and permit local citizens, officials, and organizations to hold their hospitals accountable to their social mission to improve community health. 


\section{ABOUT THIS WHITE PAPER}

This white paper is part of a series analyzing specific metrics in the Lown Institute Hospitals Index. This paper was written by Judith Garber, Shannon Brownlee, and Vikas Saini. Valérie Gopinath, Paula Smith, and Vikas Saini led the data analytics for this project.

Suggested Citation: Garber, J., Brownlee, S., Saini, V. Ranking Hospital Community Benefit Investment. Brookline, MA: The Lown Institute. 2020.

\section{METRICS ADVISORY COUNCIL}

We greatly appreciate the Lown Hospitals Index Metrics Advisory Council for lending their advice and expertise to assist in the creation of the Lown Index. The members of the MAC are listed below. Thanks to Kevin Barnett, Patty Gabow, Paul Hattis, Sara Rosenbaum, and Gary Young, who advised us on the Community Benefit metric in particular.

William B. Adams

Co-chair, Patient Council, Right Care Alliance

Kevin Barnett, DrPH, MCP

Senior Investigator, Public Health Institute

Andrew Bazemore, MD, MPH

SVP of Research and Policy, American Board of Family Medicine

David Bor

Chief Academic Officer, Cambridge Health Alliance

Candace Chen, MD, MPH

Associate Professor of Health Policy \& Management, Milken Institute School of Public Health, The George Washington University

Joanne M. Conroy, MD

CEO and President, Dartmouth-Hitchcock

Adam Elshaug

Professor of Health Policy, University of Sydney

Elmer Freeman

Executive Director, Center for Community Health Education Research and Service 
Paul Glastris

Editor in Chief, the Washington Monthly

Merrill Goozner

Editor Emeritus, Modern Healthcare

Paul A. Hattis, MD, JD, MPH

Associate Professor, Tufts University School of Medicine

Emma Hoo

Director, Pacific Business Group on Health

Jeffrey Levi

Professor of Health Policy and Management, George Washington University

Sara Rosenbaum, JD

Harold and Jane Hirsh Professor of Health Law and Policy, George Washington

University

Aaron Schwartz

Resident, Department of Internal Medicine, Brigham and Women's Hospital

Pritpal S. Tamber

Independent Writer, Researcher and Consultant

Gary J. Young, JD, PhD

Director, Northeastern University Center for Health Policy and Healthcare Research 


\section{REFERENCES}

1. Cronin CE, Bolon D. Comparing Hospital Mission Statement Content in a Changing Healthcare Field. Hospital Topics 2018; 96(1): 28-34.

2. Rosenbaum S, Kindig DA, Bao J, Byrnes MK, O'Laughlin C. The Value Of The Nonprofit Hospital Tax Exemption Was \$24.6 Billion In 2011. Health Aff (Millwood) 2015; 34(7): 1225-33.

3. Khatami E. Pittsburgh votes to expand hospital chain that won't let workers unionize. ThinkProgress. 2018.

4. Diamond D. How the Cleveland Clinic grows healthier while its neighbors stay sick. Politico. 2017.

5. Thomas WC. The Nonprofit Hospital That Makes Millions, Owns a Collection Agency and Relentlessly Sues the Poor. ProPublica. 2019.

6. Garber J, Brownlee S. What Makes A Hospital The "Best"? Health Affairs Blog 2017.

7. James J. Nonprofit Hospitals' Community Benefit Requirements. Health Affairs 2016.

8. Rosenbaum S. Hospital Community Benefit Spending: Leaning In on the Social Determinantsof Health. The Milbank quarterly 2016; 94(2): 251-4.

9. Herring B, Gaskin D, Zare H, Anderson G. Comparing the Value of Nonprofit Hospitals' Tax Exemption to Their Community Benefits. INQUIRY: The Journal of Health Care Organization, Provision, and Financing 2018; 55: 0046958017751970.

10. Young GJ, Flaherty S, Zepeda D, Singh SR, Cramer GR. Community Benefit Spending By Tax-Exempt Hospitals Changed Little After ACA. Health Affairs 2018; 37(1).

11. Kacik A. Flaws in hospital community benefit reporting create knowledge vacuum regarding community benefits. Modern Healthcare. 2018.

12. Chaiyachati KH, Qi M, Werner RM. Non-profit hospital community benefit spending based on local sociodemographics. Journal of health care for the poor and underserved 2018; 29(4): 1259-68.

13. Bai G, Yehia F, Anderson GF. Charity Care Provision by US Nonprofit Hospitals. JAMA Internal Medicine 2020; 180(4): 606-7.

14. Bannow T. Charity care spending flat among top hospitals. Modern Healthcare. 2018.

15. Diamond D. How hospitals got richer off Obamacare. Politico. 2017.

16. Alberti PM, Sutton KM, Baker M. Changes in Teaching Hospitals' Community Benefit Spending After Implementation of the Affordable Care Act. Academic Medicine 2018; 93(10): 1524-30.

17. Young GJ, Chou CH, Alexander J, Lee SY, Raver E. Provision of community benefits by tax-exempt U.S. hospitals. N Engl J Med 2013; 368(16): 1519-27.

18. Chaiyachati KH, Qi M, Werner RM. Nonprofit Hospital Community Benefit Spending and Readmission Rates. Population Health Management 2019.

19. Institute TH. Community benefit state law profiles. Baltimore, MD: UMBC, 2016.

20. Final Adverse Determination Letter: 8/4/2017. In: Treasury Dot, editor. Dallas, TX; 2017.

21. Final Determination Letter: 7/20/2018. In: Treasury Dot, editor. Dallas, TX; 2018.

22. Final Determination of Exemption. In: Treasury Dot, editor. Dallas, TX; 2019. 
23. Maryland Hospital Community Benefit Report: FY 2016. Baltimore, MD: Health Services Cost Review Commission, 2017.

24. Sean Nicholson MVP, Lawton R. Burns, Agnieshka Baumritter, and David A. Asch. Measuring Community Benefits Provided By For-Profit And Nonprofit Hospitals. Health Affairs 2000; 19(6): 168-77.

25. Greene J. Hospitals say they subsidize graduate medical education, but cost-benefit unknown. Crain's Detroit Business. 2015 July 19, 2015.

26. June 2010 MedPAC Report to the Congress: Aligning incetives in Medicare. In: Services HaH, editor.: Medicare Payment Advisory Committee; 2010.

27. Gale J, Croll Z, Coburn A, Croom J. Comparing the Community Benefit Spending of Critical Access, Other Rural, and Urban Hospitals: Flex Monitoring Team, University of Southern Maine, 2016.

28. Race M, Gale J, Coburn A. Community Benefit Activities of Critical Access Hospitals, Non-Metropolitan Hospitals and Metropolitan Hospitals: Flex Monitoring, University of Southern Maine, 2010.

29. Foden-Vencil K. Legislators Try To Make Hospitals Justify Their Nonprofit Status. Oregon Public Radio. 2019.

30. Bruhn WE, Rutkow L, Wang P, et al. Prevalence and Characteristics of Virginia Hospitals Suing Patients and Garnishing Wages for Unpaid Medical Bills. JAMA 2019. 